\title{
Levels of Need for Library Service in Academic Institutions
}

\author{
By NEAL HARLOW
}

IT is Axiomatic, off-campus at least, that academic libraries offer fewer services to their users than do the other types of libraries-public, school, and special. They provide seats, collections, some form of library "instruction," and "reference" service consisting mostly of finding material and giving assistance in its use, plus the preparation of bibliographies of fairly general scope. Some libraries do more, some do less, but this probably describes the median level of service.

Academic librarians are quick to point out that other kinds of libraries may soon discover that they cannot go on spoon-feeding their patrons either, and that whereas it may be proper enough for a special library to carry on "literature research" and provide information for its tiny clientele in a small subject field, a respectable university may have fifty or more large departmentalized subject areas with which the library has to contend, and what is done for one will soon be expected by all. They also point out that faculty members will frequently not accept an advanced level of assistance from librarians even when it is offered. Clearly, the position of the academic library is "different," and this accounts for its present character.

Academic libraries are in fact different, even among themselves. In several institutions beginning students have come in such numbers as to overwhelm library facilities as well as to constitute a problem of service on their own behalf, and "undergraduate" libraries at various levels have been set up to cope with this problem. In some places "special collec-
Mr. Harlow is Dean of the Graduate School of Library Service in Rutgers University and President of the Association of College and Research Libraries.

tions" have been established, not only to protect books and manuscripts but also to provide research facilities and assistance to qualified users. In divisional library organizations and in branch and departmental collections, "special library" services of various kinds are given systematically or on a catch-as-catch-can basis. Some of the above-median programs are the result of individual enthusiasm or concern (by librarian or faculty member); some express a well considered administrative policy of campuswide library use. Is there a basic rationale that is appropriate to academic library service which might bring the needs of all users into accurate focus or which could indicate lines of force around which needs and services might naturally cluster?

It is the hypothesis of this paper that there are distinctive levels of academic and research need in respect to library service within institutions of college and university rank, and if this be true, individual library programs can be designed to satisfy them. ${ }^{1}$ If users do divide nicely for libraries into more or less discrete if not necessarily exclusive

${ }^{1}$ See Neal Harlow, "An Open-skies System of Academic Library. Service," in the Journal of Education for Librarianship, II (1962), 183-90, particularly p. 188-89. The concept has also been fairly thoroughly canvassed in an advanced (doctoral) Seminar in Research Library Administration in the spring inar in Research Library Administration in the spring of 1963 at the Graduate School of Library Service, Rusak, Mr. Rodney F. Ferguson, and Mr. Hassan E. Hassan. 
groups, their problems can be attacked directly and logically when they are recognized. The categories of functions which will now be described do not exist in the literature of librarianship under the names which, for want of a more exact terminology, are tentatively used here, but they are carefully defined as part of the process of identification with which this paper is primarily concerned.

Hypothesis: There are three levels of library use in an academic and research institution: (1) "college" level-the student's library, for the beginning student engaged in general education and in acquiring background for specific disciplines; (2) "university" level-the maturing scholar's library, for the developing scholar and specialist, emphasizing a subject field or area, providing synthesis and an introduction to research; and (3) "research" level-for the advanced graduate, faculty member, and research staff concerned with the extension or application of knowledge providing the necessary intellectual support for research.

If these three levels of need are real and call for different kinds of library service to meet them, we can serve them better when we (a) identify them, (b) analyze their needs, and (c) design specific services to satisfy them. Rather than argue about terminology, let us concentrate upon identifying and defining needs, using the terms which are at present available to us.

The "College" Library: The Library in the Program of General Education

The "college" provides in its two academic years a foundation upon which a "general education" is built and a base for future specialization. Its program normally includes introductory and general courses in three broad divisions: the humanities, social sciences, and sciences.

The library's character and scope: The library reflects the character and content of the curriculum offered by the college. It is general in coverage, tending toward breadth in subject matter rather than depth. It provides material for assigned reading and for the encouragement and accommodation of the developing intellectual interests of growing individuals; it is the "school library" of higher education.

The library's purpose: It has a dual purpose with respect to students: (1) to constitute part of the instructional program, promoting and supplementing college teaching, and (2) to develop the student's habit of self-education through familiarity with bibliographic method and resources and the encouragement of independent work. For the faculty it provides the resources and services necessary for teaching at the college level.

Special needs of users: Students need direct access to a small and well selected collection of library materials, with a minimum of physical and psychological restraint, conditions which are attractive and conducive to study, long open hours, and a mature and respected professional staff. They need instruction and guidance in the use of bibliographic method and resources and individual attention with relation to their academic problems.

Types of resources: The library should provide a well selected, constantly weeded, and live collection of books and other materials in areas of general knowledge, covering broadly the humanities, social sciences, and sciences. It should have a small reference collection, adequate to the students' requirements at the introductory level, and a number of good quality journals, general and basic in nature.

Appropriate services: There should be plenty of pertinent material, readily accessible for home or library use, with enough copies to support required and popular reading; a knowledgeable staff with a respect for individuals and an interest in the needs of undergraduates; 
formal and informal instruction in bibliographic method-a learning that is intended to be transferable and not tied to local surroundings; a simple catalog; cooperation with faculty in making the library a laboratory that is functionally related to courses of study; encouragement of free reading through open, attractive collections, displays, book lists, reader guidance, discussion groups, readings, and dormitory libraries; and service to faculty through lists of acquisitions and information about appropriate new materials, bibliographies for class use, and the provision of special materials as required to satisfy particular assignments.

\section{ThE "University" Library: the Library Serving the Maturing Student- SPECIALIST-SCHOLAR}

Beyond the introductory college level, the "university" offers the maturing student a greater depth of general understanding, opportunities to observe relationships among a number of subject fields, and bases for continuing specialization. The student learns the attitudes and techniques of investigation, and the faculty maintains competence in his subject field and improves the effectiveness of his communication with classes.

The library's character and scope: The library provides material in sufficient depth to encourage and make possible serious scholarship in all departments in which instruction is given. It is both general in scope and specialized in the content of its holdings, providing opportunity for directed study, systematic review, summary, and evaluation.

The library's purpose: The library is designed to support the teaching program, embracing the whole curriculum above the introductory level, serving "upper division" subject "majors," honors students, and persons preparing to work toward advanced degrees; to introduce the student to the attitudes, techniques, and possibilities of investi- gation and to give him opportunity to pursue it; to offer adequate material to allow choice in reading, encouragement in following references, and reinforcement for continuing study; and to satisfy the full range of faculty needs for instructional purposes, including standard treatises and texts and the results of past and current research.

Special needs of users: The student needs training and experience in bibliographic method, acquaintance with bibliographic sources and reference works (available locally or elsewhere) in his field of study, exercise in discriminating between good and poor sources of information and in logically using his findings. He may need information rather than guidance when its use is more important to his education than his experience in finding it. The teacher will need assistance in acquainting students with the bibliography of their subject fields, in developing their own bibliographic knowledge, and in maintaining "current awareness" with respect to recent publication. Ready access to materials is essential, with facilities for uninterrupted individual study.

Types of resources: The library must embrace most subject fields, many of them to considerable depth, and have a widely representative collection of general works and of those which are common to several fields, providing historical coverage when this is appropriate, and the newest editions and most recent issues of bibliographies, reference works, serials, original texts, monographic studies, government publications, maps, microreproductions, manuscripts (or facsimiles) for instructional use, slides, recordings, and any other pertinent content without respect to physical form.

Appropriate services: Resources should be freely accessible, including "rare" materials under necessary supervision, providing opportunity for persons to work near collections of immediate interest, 
and to be able to consult bound and unbound periodicals, indexes, reference materials, and books in convenient juxtaposition. There should be instruction and assistance in bibliographic method and in the use of bibliographic and reference works; assistance in defining the bibliographic problems of specific investigations and in selecting materials to master them; and the provision of actual information when it is more important to the user than the intellectual exercise in locating it. There should be subject specialization in reference and information service to students and faculty, based upon knowledge among the library staff of the character, terminology, and literature of subject fields and a convenient organization of related materials and services to expedite use. Services should include the preparation of general and special bibliographies, interlibrary loan, assistance in translation, cheap and rapid copying, arrangements for individual study, typing facilities, and long hours of operation.

The Academic "Research" Library: the "SPECIAL" LIBRARY WITHIN THE Academic Setting

Research in an academic institution is carried on by faculty, doctoral candidates, and research staff who fulfill the university's responsibility to extend the boundaries of knowledge beyond that required to satisfy the immediate demands of teaching.

The library's character and scope: A research collection should be tailored to satisfy the specific needs of the projects it serves, acquiring only materials which contribute to this purpose, and maintaining working arrangements with other general and special libraries to assure the availability of supporting resources.

The library's purpose: to provide information and material when it is required and in the form in which it is needed, with the special responsibility to maintain current awareness in areas of present and developing concern and to stimulate new thought and learning through the continuing flow of pertinent literature.

Special needs of users: The research man in a university may use the library directly, or he may ask for special information and assistance. A specialist in a narrow subject field, he will need bibliographic guidance and support in other areas, assistance in literature searching, in scanning what is new and of interest to him, and in maintaining highly selective personal reference files.

Types of resources: Built upon the resources of the "university" library, the "research" library's collections will be of a highly specialized nature. In the sciences these may be laboratory materials such as handbooks and formulary, pertinent journals, abstracts and indexes, annual reviews, state-of-the-art series, "report" literature, and proceedings, often of recent date. In the humanities and social sciences there will be books and monographs, original texts, journals, field reports, original documents, government publications, manuscripts, newspaper files, microreproductions, ephemera, and whatever else is required, often without respect to age.

Appropriate services: The library must provide rapid procurement, processing, and binding; quick reference service; accurate information; literature searching, bibliographic checking, and the preparation of bibliographies; the screening of incoming literature for individuals and groups, including tables of contents, citations, abstracts, or photographic copies, if pertinent; "skim," "spot," or full translations; cheap and quick photocopy; telephone and delivery service, and interlibrary loan; communication with subject specialists in preparing necessary state-of-the-art summaries; seminars relating to the output of current literature; participation in faculty and research meetings and seminars, coordination of library and research in- 
terests in the university; promotion of the use of services; and study facilities for continued uninterrupted use during long open hours.

In order to provide a more extended perspective and contrast between the academic "research" library and the "special" library in a noncampus setting, a fourth category of need and service is appended.

The "SPECIAL" LibraRy: THE LibraRy SUPPORTING RESEARCH AND DEVELOPMENT IN

BUSINESS, INDUSTRY, AND GOVERNMENT

The "special" library is part of an agency, industry, business, or organization (private or government); it provides a fundamental service, correlating, interpreting, and utilizing materials for the sole benefit of its particular clientele.

The library's character and scope: The scope of the library is likely to be narrow, as determined by the active requirements of the organization of which it is a part; it will characteristically cover one or more limited subject areas of immediate or developing concern.

The library's purpose: It is normally the purpose of this library to provide information rather than material, when it is required, in the form in which it is needed, and with responsibility for its accuracy and completeness.

Special needs of users: The "bench" scientist, engineer, and technician may require special information or a summary and evaluation of literature in order to carry out their current tasks. They will need to keep up with the literature in their special fields and to have recourse to it upon demand.

Types of resources: Holdings are likely to be of current and recent date, though they will embrace whatever is of continuing use: journals, "report" literature, patents, monographs, reprints, photocopies, translations, abstracts, punched cards, magnetic tape, handbooks, tables, and other pertinent material in usable form.

Appropriate : services: Appropriate services include rapid procurement and processing; quick reference; the provision of specific, accurate, and complete information, using the assistance of subject specialists trained for this work or librarians responsible for information and materials, whichever is appropriate; access to interlibrary loan and the information network; literature searching and bibliography; screening of current literature and circulating of tables of content, citations, abstracts, or photocopies, often in bulletin form; "skim," "spot," or full translations; quick photocopy; state-of-the-art summaries; organizing seminars relating to the current literature; writing, editing, and publishing; attending staff meetings as part of the research team; working with and coordinating the use of machines for information use; maintaining archives; and harnessing information to every research requirement.

It is not likely that a library will ever be able to offer a one-level service to a constant and homogeneous group of users. In a research library (as studies have shown) most information provided is of a "general" nature; in a junior college the needs of faculty and the requirements of technical and terminal courses do not conform to normal undergraduate use; and even at the purely "college" level (as herein defined), assignments may involve quite complex investigation for the able and accelerated student. But if these academic groups can be observed in strata as described, each with its characteristic library needs, librarians should not be confused by overlapping areas of similarity. By failing to distinguish among levels of users and use, attention tends to gravitate toward the least common denominator; this is usually the student who wants to borrow a book.

Library resources are vital to the academic man, but a library system to satis- 
fy his intellectual requirements has seldom justified its existence to him. The librarian has not often thoroughly rationalized all of his relationships to the academic community, but he has rather incontinently dreamed of "the scholar's workshop" and "the heart of the university" in psychic release from responsibility!
If no "standard issue" of library service is acceptable to all users but several levels of operation are required to satisfy demonstrated needs, would a proposal to develop appropriate services in all academic libraries - as a continuing ACRL program-stir the Association's interest in its present mood and at a time like this (its 75 th anniversary)?

\section{ACRL Grants Program, 1963}

For THE NINTH consecutive year, the Committee on Grants is distributing application forms for subgrants to the libraries of privately endowed universities and colleges whose curricula constitute four-year programs of undergraduate instruction. Application forms will be mailed early in September to the librarians of the eligible institutions (privately endowed four-year universities and colleges, as listed in the USOE Education Directory, 1962-63, Part 3).

These applications must be submitted to the ACRL office not later than October 18.

The grants are designed to help develop collections, and improve the quality of library services to higher education through research in librarianship and bibliography.

Renewal of the United States Steel Foundation's gift to ACRL to support this program in 1963 has been made. The foundation has been our principal contributor since 1955. Their grant of $\$ 30,000$ also demonstrates in an effective manner the faith of the foundation in the value of this ACRL program activity.

The 1963 program has additional support from the National Biscuit Company Foundation, the Olin Mathieson Charitable Trust, Pitney Bowes Inc., Time Incorporated, and the H. W. Wilson Foundation, Inc.

The Remington Rand Division of Sperry Rand Corporation has contributed $\$ 7,500$ for the purchase of furniture and equipment which is available through the Library Bureau.

The same form will be used either for requests for a monetary grant or for requests for a grant of furniture or equipment.

Requests from individual librarians for research or bibliographical work should be made by a letter stating succinctly the purpose of the project, its current state of development, its proposed date of completion, a budget for the funds requested, and the reasons why funds from outside the applicant's own institution are sought.

Members of the Grants Committee will meet in Pittsburgh, Pa., in November to determine actual distribution of the grants. Announcement of their decision will be made in the January 1964 number of $C R L$. Mark M. Gormley, librarian, University of Wisconsin-Milwaukee, is chairman of the committee for $1963 / 64$. Other members are: Humphrey G. Bousfield, chief librarian, Brooklyn College, Brooklyn, N.Y.; Helen M. Brown, librarian, Wellesley College, Wellesley, Mass.; Wen Chao Chen, librarian, Kalamazoo College, Kalamazoo, Mich.; Richard B. Harwell, librarian, Bowdoin College, Brunswick, Me.; David Kaser, director, Joint University Libraries, Nashville, Tenn.; Neal R. Harlow, dean, Graduate School of Library Service, Rutgers University, New Brunswick, N.J. (ACRL President ex officio); and George M. Bailey (ACRL Executive Secretary ex officio). 